\title{
Electrocaloric Effect (ECE) in Ferroelectric Polymer Films
}

\author{
S. G. Lu' ${ }^{1}$, B. Rožič2 ${ }^{2}$ Z. Kutnjak ${ }^{2}$ and Q. M. Zhang ${ }^{1}$ \\ ${ }^{1}$ Materials Research Institute and Department of Electric Engineering, \\ The Pennsylvania State University, University Park, PA 16802 \\ ${ }^{2} J o z e f$ Stefan Institute, 1000 Ljubljana \\ ${ }^{1}$ USA \\ ${ }^{2}$ Slovenia
}

\section{Introduction}

The electrocaloric effect (ECE) is the change in temperature and/or entropy of a dielectric material due to the electric field induced change of dipolar states. Electrocaloric effect in dielectrics is directly related to the polarization changes under electric field.[1-3,6] Hence a large polarization change is highly desirable in order to achieve a large ECE which renders the ferroelectric materials the primary candidates for developing materials with large ECE. Figure 1 illustrates schematically the ECE in a dipolar material. Application of an electric field to the material causes partial alignment of dipoles and consequently a reduction of entropy of the dipolar system. In an isothermal condition, the dipolar material rejects heat $\mathrm{Q}=\mathrm{T} \Delta \mathrm{S}$ to the surrounding, where $\mathrm{T}$ is the temperature and $\Delta \mathrm{S}$ is the isothermal entropy change. Or in an adiabatic process, to keep the total entropy of the material constant, the temperature of the dielectric is increased by $\Delta \mathrm{T}$, the adiabatic temperature change which is related to the $Q=C \Delta T$ where $C$ is specific heat capacity of the dielectric. In a reverse process, as the applied electric field is reduced to zero and the dipoles return to the less ordered state (or disordered state), an increase in the entropy of dipolar system occurs and under an isothermal condition, the dielectric will absorb heat $Q$ from the surrounding.

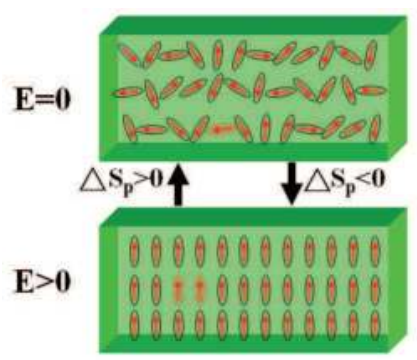

Fig. 1. Schematic drawing of the ECE process in a dipolar material. When $E=0$, the dipoles orient randomly. When $\mathrm{E}>0$, especially larger than the coercive electric field, the dipoles orient along the electric field direction. 
The ECE may provide an effective means of realizing solid-state cooling devices for a broad range of applications such as on-chip cooling and temperature regulation for sensors or other electronic devices. Refrigerations based on ECE have the potential of reaching high efficiency relative to vapor-compression cycle systems, and no green house emission.

Solid-state electric-cooling devices based on the thermoelectric effect (Peltier effect) have been used for many decades (Spanner, 1951; Nolas, Sharp, and Goldsmid, 2001). However, these cooling devices require a large DC current which results in large amount of waste heat through Joule heating. For example, using the typical coefficient of performance (COP) for these devices, e.g. 0.4 to $0.7,2.4$ to 3.5 watts of heat will be generated at the hot end of the system when pumping 1 watt heat from the cold end. Hence, the thermoelectric effect based cooling devices will not meet the requirement of high energy efficiency.

A counterpart of ECE is the MCE, which has been extensively studied for many years due to the findings of giant magnetocaloric effect in several magnetic materials near room temperature (Gschneidner Jr., Pecharsky and Tsokol, 2005; Pecharsky, Holm, Gschneidner Jr. and Rink, 2003). Both ECE and MCE devices exploit the change of order parameter brought about by an external electric or magnetic field. However, the difficulty of generating high magnetic field for MCE devices to reach giant $\mathrm{MCE}$, severely limits their wide applications. This makes the MCE devices difficult to be used widely, especially for miniaturized microelectronic devices, and to achieve high efficiency. In contrast, high electric field can be easily generated and manipulated, which makes ECE based cooling devices attractive and more practical for a broad range of applications.

This chapter will introduce the basic concept of ECE, the thermodynamic considerations on materials with large ECE, and review previous investigations on the ECE in polar crystals, ceramics, and thin films. A newly discovered large ECE in ferroelectric polymers will be presented. Besides, we will also discuss different characterization techniques of ECE such as the direct measurements and that deduced from Maxwell relations, as well as phenomenological theory on ECEs.

\section{Thermodynamic considerations on materials with large ECE}

\subsection{Maxwell relations}

In general the Gibbs free energy $G$ for a dielectric material could be expressed as a function of temperature $T$, entropy $S$, stress $X$, strain $x$, electric field $E$ and electric displacement $D$ in the form

$$
G=U-T S-X_{i} x_{i}-E_{i} D_{i},
$$

where $U$ is the internal energy of the system, the stress and field terms are written using Einstein notation. The differential form of Eq. (1) could be written as

$$
d G=-S d T-x_{i} d X_{i}-D_{i} d E_{i} .
$$

Entropy $S$, strain $x_{i}$ and electric displacement $D_{i}$ can be easily expressed when the other two variables are assumed to be constant,

$$
S=-\left(\frac{\partial G_{1}}{\partial T}\right)_{X, D}, x_{i}=-\left(\frac{\partial G_{1}}{\partial X_{i}}\right)_{T, D}, D_{i}=-\left(\frac{\partial G_{1}}{\partial E_{i}}\right)_{T, X} .
$$


The Maxwell relation can be derived for $(\mathrm{S}, \mathrm{T})$ and $(\mathrm{D}, \mathrm{E})$ two pairs of parameters (Line and Glass, 1977),

$$
\left(\frac{\partial S}{\partial E_{i}}\right)_{T, X}=\left(\frac{\partial D_{i}}{\partial T}\right)_{E, X} .
$$

Or

$$
\left(\frac{\partial T}{\partial E}\right)_{S}=\frac{T}{c_{E}}\left(\frac{\partial D}{\partial T}\right)_{E}=\frac{T p_{E}}{c_{E}},
$$

where $c_{E}$ is the heat capacity, $p_{E}$ the pyroelectric coefficient. Eqs. (4) and (5) indicate the mutually inverse relationships of ECE and the pyroelectric coefficient. Hence, for the ECE materials with a constant stress $X$ imparted, the isothermal entropy change $\Delta S$ and adiabatic temperature change $\Delta \mathrm{T}$ can be expressed as (Line and Glass, 1977)

$$
\begin{gathered}
\Delta S=-\int_{E_{1}}^{E_{2}}\left(\frac{\partial D}{\partial T}\right)_{E} d E, \\
\Delta T=-\frac{T}{\rho} \int_{E_{1}}^{E_{2}} \frac{1}{c_{E}}\left(\frac{\partial D}{\partial T}\right)_{E} d E .
\end{gathered}
$$

Equations (4) through (7) indicate that in order to achieve large $\Delta \mathrm{S}$ and $\Delta \mathrm{T}$, the dielectric materials should posses a large pyroelectric coefficient over a relatively broad electric field and temperature range. For ferroelectric materials, a large pyroelectric effect exists near the ferroelectric $(\mathrm{F})$ - paraelectric $(\mathrm{P})$ phase transition temperature and this large effect may be shifted to temperatures above the transition temperature when an external electric field is applied. It is also noted that a large $\Delta T$ may be achieved even if $\Delta S$ is small when the $c_{E}$ of a dielectric material is small. However, as will be pointed out in the following paragraph, this is not desirable for practical refrigeration applications where a large $\Delta S$ is required.

It is noted that in the temperature region including a first-order FE-PE transition, Eq. (6) should be modified to take into account of the discontinuous change of the polarization $\Delta \mathrm{D}$ at the transition, i.e.,

$$
\Delta S=-\int_{0}^{E}\left(\frac{d D}{d T}\right)_{E} d E+\Delta D\left(\frac{\partial E}{\partial T}\right) .
$$

Although a few studies on the ECE were conducted in which direct measurement of $\Delta \mathrm{T}$ was made (Sinyavsky, Pashkov, Gorovoy, Lugansky, and Shebanov, 1989; Xiao, Wang, Zhang, Peng, Zhu and Yang, 1998), most experimental studies were based on the Maxwell relations where the electric displacement $\mathrm{D}$ versus temperature $\mathrm{T}$ under different electric fields was characterized. $\Delta S$ and $\Delta T$ were deduced from Eqs. (6) and (7) (see below for details). For dielectric materials with low hysteresis loss and the measurement is in an ideal situation, results obtained from the two methods should be consistent with each other. However, as will be shown later that for the relaxor ferroelectric polymers, the ECE deduced from the 
Maxwell relations can be very different from that measured directly and hence the Maxwell relations cannot be used for these materials in deducing ECE. In general, the Maxwell relations are valid only for thermodynamically equilibrium and ergodic systems.

In an ideal refrigeration cycle the working material (refrigerant) must absorb entropy (or heat) from the cooling load while in thermal contact with the load (isothermal entropy change $\Delta S$ ). The material is then isolated from the load while the temperature is increased due to the application of external field (adiabatic temperature change $\Delta \mathrm{T}$ ). The material is then in thermal contact with the heat sink and entropy that was absorbed from the cooling load is rejected to the heat sink. The working material is then isolated from the heat sink and the temperature is reduced back as the field is reduced. The temperature of the refrigerant will be the same as the temperature of the cooling load when they are contacted. The whole process is repeated to further reduce the temperature of the load. Therefore, both the isothermal entropy change $\Delta S$ and the adiabatic temperature change $\Delta \mathrm{T}$ are the key parameters for the ECE of a dielectric material for refrigeration (Wood and Potter, 1985; Kar-Narayan and Mathur, 2009).

\subsection{Phenomenological theory of ECE}

Phenomenological theory has been widely utilized to illustrate the macroscopic phenomena that occur in the polar materials, e.g. ferroelectric or ferromagnetic materials near their phase transition temperatures. The general form of the Gibbs free energy associated with the polarization can be expressed as a series expansion in terms of the electric displacement (Line and Glass, 1977)

$$
G=\frac{1}{2} \alpha D^{2}+\frac{1}{4} \xi D^{4}+\frac{1}{6} \zeta D^{6},
$$

where $\alpha=\beta\left(T-T_{0}\right)$, and $\beta, \xi$ and $\zeta$ are assumed to be temperature-independent phenomenological coefficients. From $\left(\frac{\partial G}{\partial T}\right)_{D}=-\Delta S$, one can obtain,

$$
\Delta S=-\frac{1}{2} \beta D^{2}
$$

Then the adiabatic temperature change $\Delta \mathrm{T}\left(=\mathrm{T} \Delta \mathrm{S} / \mathrm{C}_{\mathrm{E}}\right)$ can be obtained, i.e.

$$
\Delta T=-\frac{1}{2 c_{E}} \beta T D^{2}
$$

Based on Eqs. (9) and (10), the entropy will be reduced when the material changes to a polar state from a non-polar state when an external action, e.g. temperature, electric field or stress, is applied. The entropy change and temperature change are associated with the phenomenological coefficient $\beta$ and electric displacement $D$, viz. proportional to $\beta$ and $D^{2}$. Both parameters will affect the ECE values of the materials. A material with large $\beta$ and large D will generate large ECE entropy change and temperature change near the ferroelectric $(\mathrm{F})$ - paraelectric $(\mathrm{P})$ phase transition temperature.

\subsection{ECE in several ferroelectric materials}

Based on the literature reported values of $\beta$ and $D$, the ECE values of various ferroelectric materials could be estimated. For instance, for $\mathrm{BaTiO}_{3}, \beta=6.7 \times 10^{5}\left(\mathrm{JmC}^{-2} \mathrm{~K}^{-1}\right)$ and $\mathrm{D}=0.26$ 
$\mathrm{C} / \mathrm{m}^{2}$ (Jona and Shirane, 1993; Furukawa, 1984), $\Delta \mathrm{S}$ will be approximately $3 \mathrm{~J} /(\mathrm{kgK})$. Using the specific heat $\mathrm{c}_{\mathrm{E}}=4.07 \times 10^{2} \mathrm{~J} /(\mathrm{kgK})$ and $\mathrm{T}_{\mathrm{c}}=107^{\circ} \mathrm{C}$ (Jona and Shirane, 1993; Akay, Alpay Mantese, and Rossetti $\mathrm{Jr}, 2007)$, results in a $\Delta \mathrm{T}=2.8{ }^{\circ} \mathrm{C}$. Similarly, for $\mathrm{Pb}\left(\mathrm{Zr}_{\mathrm{x}} \mathrm{Ti}_{1-\mathrm{x}}\right) \mathrm{O}_{3}$ $(0.0<x \leq 0.6), \beta=1.88 \times 10^{5}$ and $\mathrm{D}=0.39 \mathrm{C} / \mathrm{m}^{2}$ (Amin, Cross, and Newnham, 1981; Amin, Newnham, and Cross, 1981), one will obtain $\Delta S=1.8 \mathrm{~J} /(\mathrm{kgK})$. Taking $\mathrm{T}_{\mathrm{c}}=250{ }^{\circ} \mathrm{C}$, and $\mathrm{c}_{\mathrm{E}}=$ $3.4 \times 10^{2} \mathrm{~J} /(\mathrm{kgK})\left(\right.$ PI Ceramic website, 2009), will result in $\Delta \mathrm{T}=2.7^{\circ} \mathrm{C}$.

For ferroelectric polymers, e.g. $\mathrm{P}(\mathrm{VDF}-\mathrm{TrFE})$, phenomenological theory predicts large ECE values. For example, $\mathrm{P}(\mathrm{VDF}-\mathrm{TrFE}) 65 / 35 \mathrm{~mol} \%$ copolymer, with $\beta=3.5 \times 10^{7} \mathrm{JmC}^{-2} \mathrm{~K}^{-1}$ and $\mathrm{D}$ $=0.08 \mathrm{C} / \mathrm{m}^{2}$ (Furukawa, 1984), will exhibit a $\Delta \mathrm{S}=62 \mathrm{~J} /(\mathrm{kgK})$. Making use of its specific heat capacity $\mathrm{c}_{\mathrm{E}}=1.4 \times 10^{3} \mathrm{~J} /(\mathrm{kgK})$ (Furukawa, Nakajima, and Takahashi, 2006) and Curie temperature $\mathrm{T}_{\mathrm{c}}=102{ }^{\circ} \mathrm{C}$ (Furukawa $\mathrm{T}, 1984$ ), yields $\Delta \mathrm{T}=16.6^{\circ} \mathrm{C}$. The large $\Delta \mathrm{S}$ and $\Delta \mathrm{T}$ values suggest that a large ECE may be achieved in ferroelectric $\mathrm{P}(\mathrm{VDF}-\mathrm{TrFE})$ copolymers. Furthermore, relaxor ferroelectric polymers based on P(VDF-TrFE), such as P(VDF-TrFECFE) 59.2/33.6/7.2 mol\% (CFE-chlorofluoroethylene) relaxor ferroelectric terpolymers also have potential to reach a large ECE because the $\beta$ and D are still large.

It was found that $\beta$ of ferroelectric ceramics $\left(\sim 10^{5}\right)$ is about two orders of magnitude smaller than that of $\mathrm{P}(\mathrm{VDF}-\mathrm{TrFE})\left(\sim 10^{7}\right)$. D however is only several times higher for ceramics, since $\Delta S \sim \beta D^{2}, \Delta S$ is still about one order of magnitude smaller than that of the P(VDF-TrFE) based polymers.

In addition, the heat of F-P phase transition can also be used to assess the ECE $(\mathrm{Q}=\mathrm{T} \Delta \mathrm{S})$ in a ferroelectric material at temperatures above the F-P transition. For a very strong orderdisorder ceramic system (an example of which is the ferroelectric ceramic triglycine sulphate, TGS), the heat of F-P phase transition is $2.0 \times 10^{3} \mathrm{~J} / \mathrm{kg}$ (corresponding to an entropy change of $\Delta S \sim 6.1 \mathrm{~J} /(\mathrm{kgK}))$. For $\mathrm{BaTiO}_{3}, \mathrm{~F}-\mathrm{P}$ heat is smaller $9.3 \times 10^{2} \mathrm{~J} / \mathrm{kg}(\Delta S \sim 2.3$ $\mathrm{J} /(\mathrm{kgK})$ ) (Jona and Shirane, 1993). In other words, although ceramic materials may exhibit a higher adiabatic temperature change, their isothermal entropy change may not be very high. In contrast, ferroelectric polymers offer higher heat of transition in a F-P transition. For instance, $\mathrm{P}(\mathrm{VDF}-\mathrm{TrFE}) 68 / 32 \mathrm{~mol} \%$ copolymer shows a heat of F-P transition of more than $2.1 \times 10^{4} \mathrm{~J} / \mathrm{kg}$ (or $\Delta \mathrm{S} \sim 56.0 \mathrm{~J} /(\mathrm{kgK})$ ) (Neese, Chu, Lu, Wang, Furman and Zhang, 2008). This is approximately 10 times larger than its inorganic counterparts.

\section{Investigations on ECE in polar materials}

\subsection{ECE studies in ferroelectric ceramics and single crystals}

The history of ECE study may be traced back to as early as 1930s. In 1930, Kobeko and Kurtschatov did a first investigation on ECE in Rochelle salt (Kobeko and Kurtschatov, 1930), however they did not report any numerical values. In 1963, Wiseman and Kuebler redid their measurements (Wiseman and Kuebler, 1963), obtaining $\Delta \mathrm{T}=0.0036{ }^{\circ} \mathrm{C}$ in an electric field of $1.4 \mathrm{kV} / \mathrm{cm}$ at $22.2^{\circ} \mathrm{C}$. In their study, the Maxwell relation was used to derive $\Delta T\left(\Delta T=-\frac{T}{c_{E}} \frac{\partial \alpha}{\partial T} D \Delta D\right)$, where $\alpha=1 / \varepsilon$ as defined in Eq. (8) and $\varepsilon$ is the permittivity). The isothermal entropy change was $28.0 \mathrm{~J} / \mathrm{m}^{3} \mathrm{~K}\left(1.56 \times 10^{-2} \mathrm{~J} /(\mathrm{kgK})\right)$.

Other studies on inorganic materials used $\mathrm{KH}_{2} \mathrm{PO}_{4}$ crystal, and $\mathrm{SrTiO}_{3}, \mathrm{~Pb}\left(\mathrm{Sc}_{0.5} \mathrm{Ta}_{0.5}\right) \mathrm{O}_{3}$, and $\mathrm{Pb}_{0.98} \mathrm{Nb}_{0.02}\left(\mathrm{Zr}_{0.75} \mathrm{Sn}_{0.20} \mathrm{Ti}_{0.05}\right)_{0.98} \mathrm{O}_{3}$ ceramics. For $\mathrm{KH}_{2} \mathrm{PO}_{4}$ crystal, Maxwell relation was used in the form of $\Delta T=-\left(T / c_{E}\right)\left(\frac{\partial D / \partial T}{\partial D / \partial E}\right) d D$ to obtain $\Delta T=1{ }^{\circ} \mathrm{C}$ for a $11 \mathrm{kV} / \mathrm{cm}$ electric field and an entropy change of $2.31 \times 10^{3} \mathrm{~J} / \mathrm{m}^{3} \mathrm{~K}$ (or $0.99 \mathrm{~J} /(\mathrm{kgK})$ ) (Baumgartner, 1950). For $\mathrm{SrTiO}_{3}, \Delta \mathrm{T}$ 
$=1{ }^{\circ} \mathrm{C}$ and $\Delta \mathrm{S}=34.63 \mathrm{~J} / \mathrm{m}^{3} \mathrm{~K}\left(6.75 \times 10^{-3} \mathrm{~J} /(\mathrm{kgK})\right)$ under $5.42 \mathrm{kV} / \mathrm{cm}$ electric field at $4 \mathrm{~K}$ from Eq. (7) (Lawless and Morrow, 1977). For $\mathrm{Pb}\left(\mathrm{Sc}_{0.5} \mathrm{Ta}_{0.5}\right) \mathrm{O}_{3}$, a $\Delta \mathrm{T}=1.5^{\circ} \mathrm{C}$ and $\Delta \mathrm{S}$ of $1.55 \times 10^{4}$ $\mathrm{J} / \mathrm{m}^{3} \mathrm{~K}(1.76 \mathrm{~J} /(\mathrm{kgK}))$ were measured directly for a sample under $25 \mathrm{kV} / \mathrm{cm}$ field at $25{ }^{\circ} \mathrm{C}$ (Sinyavsky and Brodyansky, 1992). For $\mathrm{Pb}_{0.98} \mathrm{Nb}_{0.02}\left(\mathrm{Zr}_{0.75} \mathrm{Sn}_{0.20} \mathrm{Ti}_{0.05}\right)_{0.98} \mathrm{O}_{3}, \Delta \mathrm{T}=2.5{ }^{\circ} \mathrm{C}$ and $\Delta \mathrm{S}=1.73 \times 10^{4} \mathrm{~J} / \mathrm{m}^{3} \mathrm{~K}(2.88 \mathrm{~J} /(\mathrm{kgK}))$ at $30 \mathrm{kV} / \mathrm{cm}$ and $161^{\circ} \mathrm{C}$ deduced from Eq. (7) (Tuttle and Payne, 1981).

A direct ECE measurement was carried out for $(1-\mathrm{x}) \mathrm{Pb}\left(\mathrm{Mg}_{1 / 3} \mathrm{Nb}_{2 / 3}\right) \mathrm{O}_{3}-\mathrm{xPbTiO} 3(\mathrm{x}=0.08,0.10$, $0.25)$ ceramics near room temperature using a thermocouple when a dc electric field was applied (Xiao, Wang, Zhang, Peng, Zhu and Yang, 1998). A temperature change of $1.4{ }^{\circ} \mathrm{C}$ was observed for $x=0.08$ although at high temperatures (as $x$ increased), this change was reduced. This high ECE can be accounted for by considering the electric field-induced firstorder phase transition from the mean cubic phase to $3 \mathrm{~m}$ phase.

These results indicate that the ECE in ceramic and single crystal materials are relatively small, viz. $\Delta \mathrm{T}<2.5^{\circ} \mathrm{C}$, and $\Delta \mathrm{S}<2.9 \mathrm{~J} /(\mathrm{kgK})$, mainly because the breakdown field is low, using applied electric fields that are less than $3 \mathrm{MV} / \mathrm{m}$. Defects existing in bulk materials cause early breakdown and empirically the breakdown electric field was inversely proportional to the material's thickness. For piezoelectric ceramics, the breakdown field (in $\mathrm{kV} / \mathrm{cm}$ ) is related to the thickness (in $\mathrm{cm}$ ) via the relationship, $\mathrm{E}_{\mathrm{b}}=27.2 \mathrm{t}^{-0.39}$, indicating that thin films are more appropriate for an ECE study. Additionally, the breakdown field of dielectric polymers can be several orders of magnitude higher than ceramics, suggesting polarpolymers are good candidates for ECE investigations.

\subsection{ECE in ferroelectric and antiferroelectric thin films}

In 2006, Mischenko et al. investigated ECE in sol-gel derived antiferroelectric $\mathrm{PbZr}_{0.95} \mathrm{Ti}_{0.05} \mathrm{O}_{3}$ thin films near the F - P transition temperature. In their study, films with $350 \mathrm{~nm}$ thickness were used to allow for electric fields as high as $48 \mathrm{MV} / \mathrm{m}$. An adiabatic temperature change of $12{ }^{\circ} \mathrm{C}$ was obtained (as deduced from Eq. (7)) at $226^{\circ} \mathrm{C}$, slightly above the phase transition temperature $\left(222^{\circ} \mathrm{C}\right)$ (Mischenko, Zhang, Scott, Whatmore and Mathur, 2006). Both the high electric field and the high operation temperature near phase transition contribute to the large $\Delta \mathrm{T}\left(=\mathrm{T} \Delta \mathrm{S} / \mathrm{C}_{\mathrm{E}}\right)$. On the other hand, its isothermal entropy change is estimated to be 8 $\mathrm{J} /(\mathrm{kgK})$, which is not high compared with magnetic alloys exhibiting giant magnetocaloric effect (MCE) near room temperature, where $\Delta S \geq 30 \mathrm{~J} /(\mathrm{kgK})$ was observed (Provenzano, Shapiro and Shull, 2004). As stated previously, for high performance refrigerants, a large $\Delta S$ is necessary (Wood and Potter, 1985).

To reduce the operational temperature for large ECE in ceramic thin films, Correia et al. successfully fabricated $\mathrm{PbMg}_{1 / 3} \mathrm{Nb}_{2 / 3} \mathrm{O}_{3}-\mathrm{PbTiO}_{3}$ thin films with perovskite structure using $\mathrm{PbZr}_{0.8} \mathrm{Ti}_{0.2} \mathrm{O}_{3}$ seed layer on $\mathrm{Pt} / \mathrm{Ti} / \mathrm{TiO}_{2} / \mathrm{SiO}_{2} / \mathrm{Si}$ substrates (Correia, Young, Whatmore, Scott, Mathur and Zhang, 2009). A temperature change of $\Delta \mathrm{T}=9 \mathrm{~K}$ was achieved at $25^{\circ} \mathrm{C}$. An entropy change of $9.7 \mathrm{~J} /(\mathrm{kgK})$ can be deduced. A significant difference for ferroelectric thin films is that the largest $\Delta \mathrm{T}$ occurs at $25^{\circ} \mathrm{C}$, near the depolarization temperature $\left(18^{\circ} \mathrm{C}\right)$, not above the permittivity peak temperature. The large ECE only happens at field heating. Transitions for stable and metastable polar nanoregions (PNR) to nonpolar regions are accounted for by observed phenomena. Interactions of PNRs are similar to that between the dipoles in a glass. The field-induced phase transition has been observed in PMN-PT single crystals (Lu, Xu and Chen, 2005; Ye and Schmid, 1993). Thermal history has a critical impact on the field-induced phase transition. Relaxor ferroelectrics are of great interest due to their 
phase transition temperatures being near or at room temperature. The field induced phase transition may produce larger polarization, e.g. induced polarization, $\left\langle\mathrm{P}_{\mathrm{d}}\right\rangle$, which can lead to larger $\mathrm{dP} / \mathrm{dT}$ as well as large $\Delta \mathrm{S}$ and $\Delta \mathrm{T}$.

For thin film, the substrate must be taken into account as it may exert stresses on the thin film due to the misfit of the lattices and electromechanical coupling from the strain changes under electric field. The free energy of thin film is subject to lateral clamping and may be expressed as (Akay, Alpay Mantese, and Rossetti Jr, 2007)

$$
G_{f i l m}=G_{0}+\tilde{\alpha} D^{2}+\tilde{\xi} D^{4}+\tilde{\zeta} P^{6}-E P+G_{\text {strain }},
$$

where

$$
\tilde{\alpha}=\alpha-2 u_{m} Q_{12} \tilde{C}
$$

and

$$
\tilde{\beta}=\beta+Q_{12}^{2} \tilde{C}
$$

are the modified phenomenological coefficients, $G_{s t r a i n}=u_{m}^{2} \tilde{C}$ is the polarization-free strain energy, $\tilde{C}=C_{11}+C_{12}-2 C_{12}^{2} / C_{11}, C_{i j}$ are the elastic constants at constant polarization, $\mathrm{Q}_{\mathrm{ij}}$ are the cubic electrostrictive coefficients, and $u_{m}$ is the in-plane misfit strain. The phase transition temperature varies linearly with the lattice misfit strain via Eq. (12) while the twodimensional clamping is illustrated by Eq. (13). The excess entropy $S_{E}^{X S}$ and specific heat $\Delta \mathrm{C}_{\mathrm{E}}$ of the ferroelectric phase transition follow the form (Akay, Alpay Mantese, and Rossetti Jr, 2007),

$$
\begin{gathered}
S_{E}^{X S}(T, E)=-T\left(\frac{\partial G(D)}{\partial T}\right)_{E} \\
\Delta C_{E}(T, E)=-T\left(\frac{\partial^{2} G(D)}{\partial T^{2}}\right)_{E} .
\end{gathered}
$$

It was found that for $\mathrm{BaTiO}_{3}$ (BTO) thin film deposited on substrate, perfect lateral clamping of BTO will transform the discontinuous phase transition (1 ${ }^{\text {st }}$ order phase transition) into a continuous one. Accordingly the polarization and the specific heat capacity will be reduced near the phase transition temperature. On the other hand, based on Eqs. (12) and (13), adjustment of misfit strain in epitaxial ferroelectric thin films may vary the magnitude and temperature dependencies of their ECE properties.

\section{Large ECE in ferroelectric polymer films}

\subsection{Direct method to measure ECE}

Although most of the ECE studies rely on Maxwell relation (indirect method) to deduce the ECE of a material, it is always desirable to directly measure ECE in a dielectrics as refrigerants in cooling devices, i.e., to directly measure the isothermal entropy change $\Delta S$ and adiabatic temperature change $\Delta \mathrm{T}$ induced by a change in the applied field (direct 
method). In our study, both the indirect method and direct method were employed to characterize the ECE in polymer films. The direct comparison of the results from two methods can also shed light on how reliable the indirect method is in deducing the ECE from a ferroelectric material.

There are several methods that have been used in measuring the magnetocaloric effect (MCE) in terms of measuring the isothermal entropy change and adiabatic temperature change, such as thermocouple (Dinesen, Linderoth and Morup, 2002; Lin, $\mathrm{Xu}$ and Zhang, 2004; Spichkin, Derkachb, Tishin, Kuz'min, Chernyshov, Gschneidner Jr, and Pecharsky, 2007), thermometer (Gopal, Chahine and Bose, 1997), and calorimeter (Tocado, Palacios and Burriel, 2005; Pecharsky, Moorman and Gschneidner, Jr, 1997).

Here, a high resolution calorimeter was used to measure the sample temperature variation due to ECE when an external electric field was applied (Yao, Ema and Garland, 1998). The temperature signal was measured by a small bead thermistor. A step-like pulse was generated by a functional generator to change the applied electric field in the film, and the width of the pulse was chosen so that the sample can reach thermal equilibrium with surrounding bath. Due to the fast electric as well as thermal response (ECE) of the polymer films (in the order of tens of milliseconds (Furukawa, 1989), a simple zero-dimensional model to describe the thermal process can be applied with sufficient accuracy. In a relaxation mode, the temperature $\mathrm{T}(\mathrm{t})$ of the whole sample system can be measured, which has an exponential relationship with time, i.e.

$$
T(t)=T_{\text {bath }}+\Delta T e^{-t / \tau},
$$

where $T_{\text {bath }}$ is the initial temperature of the film, $\Delta T$ the temperature change of the polymer film. The total temperature change $\Delta \mathrm{T}_{\mathrm{EC}}$ of the whole sample system was measured, which can be expressed as $\Delta \mathrm{T}_{\mathrm{EC}}=\Delta \mathrm{T} \sum \mathrm{C}_{\mathrm{p}}^{\mathrm{i}} / \mathrm{C}_{\mathrm{p}}^{\mathrm{EC}}$. Here, $\mathrm{C}_{\mathrm{p}}^{\mathrm{i}}$ represents the heat capacity of each subsystem, $\mathrm{C}_{\mathrm{p}}^{\mathrm{EC}}$ is the heat capacity of the polymer film covered with electrode. $\Delta \mathrm{T}_{\mathrm{EC}}$ was measured as a function of temperature at constant electric field and as a function of electric field at constant temperature. $\Delta S$ can be determined from $T \Delta S=C_{p}^{i} \Delta T$.

\subsection{ECE in the normal ferroelectric P(VDF-TrFE) 55/45 mol\% copolymer 4.2.1 Experimental results of ECE}

As indicated in Section 2, the ferroelectric copolymer may produce large ECE near its phase transition temperature. $\mathrm{P}(\mathrm{VDF}-\mathrm{TrFE}) 55 / 45 \mathrm{~mol} \%$ was chosen because its F-P phase transition is of second-order (continuous), thus avoiding the thermal hysteresis effect associated with the first-order phase transition. In addition, among all available P(VDFTrFE) copolymers, this composition exhibits the lowest F-P phase transition temperature ( $70{ }^{\circ} \mathrm{C}$ ), which is favorable for refrigeration near room temperature.

Polymer films used for the indirect ECE measurement were prepared using a spin-casting method on metalized glass substrates. The film thickness for this study was in the range of $0.4 \mu \mathrm{m}$ to $1 \mu \mathrm{m}$. The free-standing films for the direct ECE measurement were fabricated using a solution cast method and the film thickness is in the range of $4 \mu \mathrm{m}$ to $6 \mu \mathrm{m}$. Figure 2 shows the permittivity as a function of temperature for P(VDF-TrFE) 55/45 mol\% copolymers measured at $1 \mathrm{kHz}$. It can be seen that the thermal hysteresis between the heating and cooling runs is pretty small $\left(\sim 1^{\circ} \mathrm{C}\right)$. The remanent polarization as a function of 
temperature shown in Fig. 3 further indicates a second-order phase transition occurred in the material. The phase transition temperature is about $70{ }^{\circ} \mathrm{C}$, and the glass transition temperature is about $-20^{\circ} \mathrm{C}$. At temperature higher than $100{ }^{\circ} \mathrm{C}$, the loss tangent rises sharply, which is associated with the thermally activated conduction.

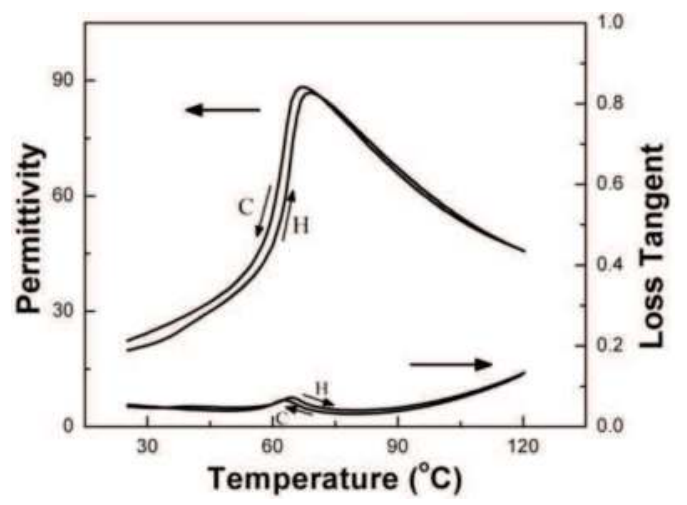

Fig. 2. Permittivity as a function of temperature for $\mathrm{P}(\mathrm{VDF}-\mathrm{TrFE}) 55 / 45 \mathrm{~mol} \%$ copolymers.

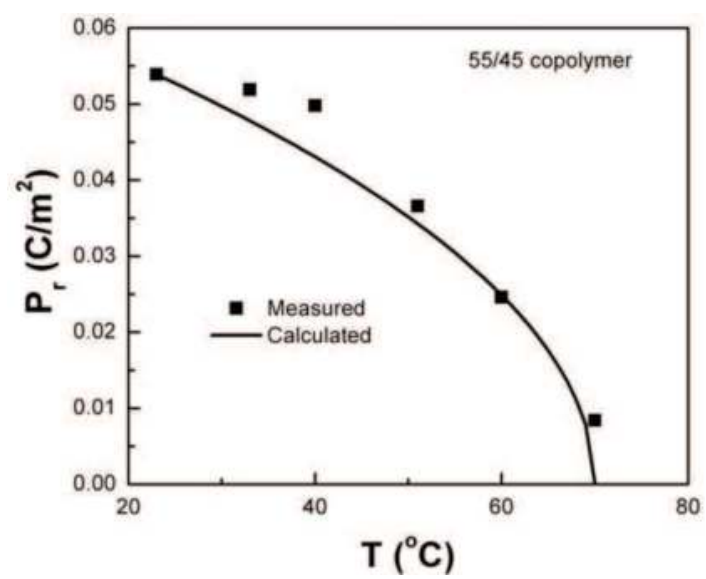

Fig. 3. Remanent polarization as a function of temperature for $\mathrm{P}(\mathrm{VDF}-\mathrm{TrFE}) 55 / 45 \mathrm{~mol} \%$ copolymers.

Figure 4 shows the electric displacement as a function of electric field measured at various temperatures. At temperatures below the transition temperature, the polymer film is in a ferroelectric state, the normal hysteresis loop is observed while at higher temperatures, the loop becomes slimed, remanent polarization diminishes, and saturation polarization still exists. Hence the electric displacement as a function of electric field at different temperatures can be procured, which is presented in Fig. 5 (Neese, 2009). One can see that the electric displacement monotonically decreases with temperature above the phase transition. The Maxwell relations were used to calculate the isothermal entropy change and adiabatic temperature change as a function of ambient temperature. The results deduced are presented in Figs. 6 and 7. 

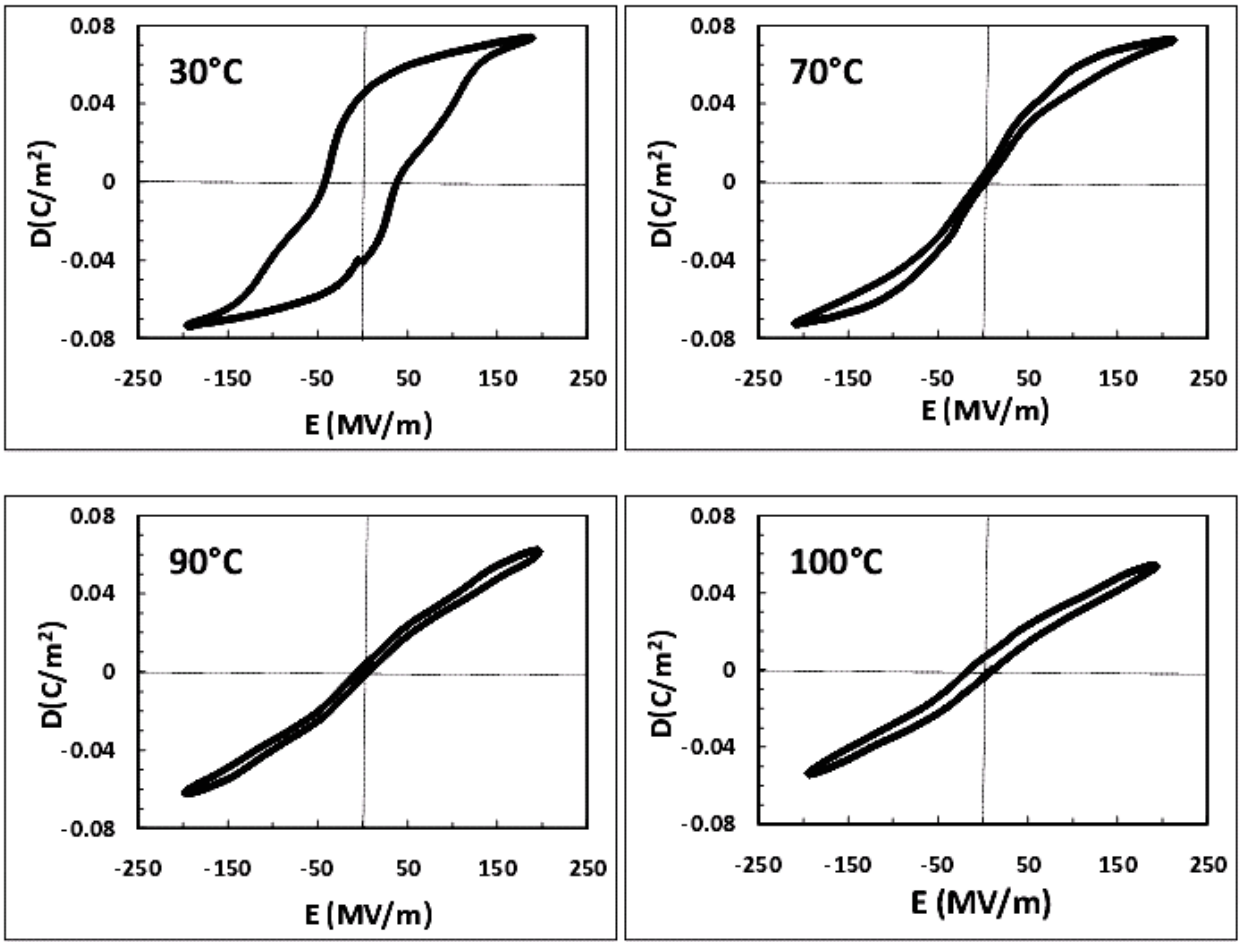

Fig. 4. Electric displacement - electric field hysteresis loops at temperature below and above the phase transition.

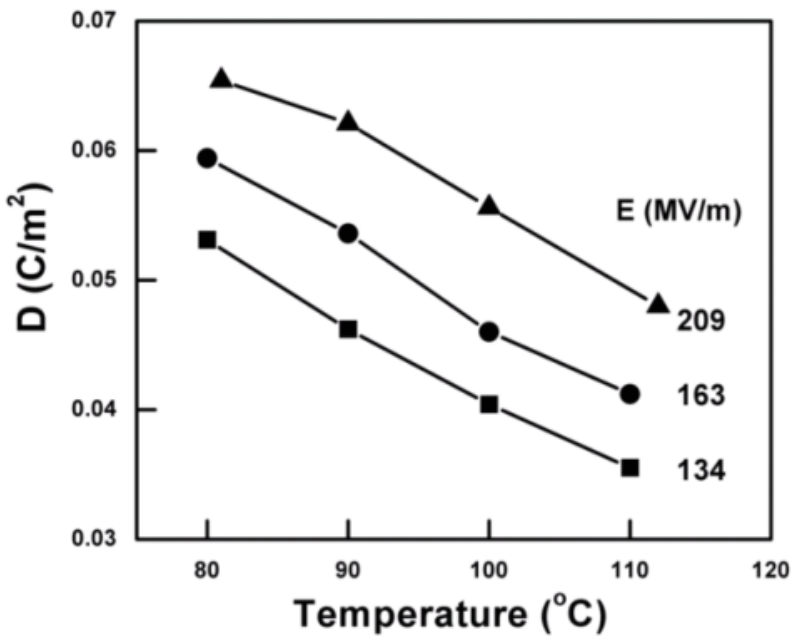

Fig. 5. Electric displacement as a function of temperature at different electric fields for $\mathrm{P}(\mathrm{VDF}-\mathrm{TrFE}) 55 / 45 \mathrm{~mol} \%$ copolymers. 


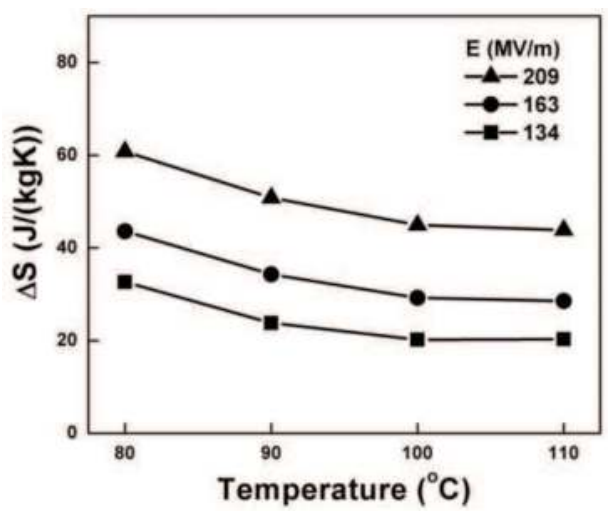

Fig. 6. Isothermal entropy changes as a function of ambient temperature at different electric fields.

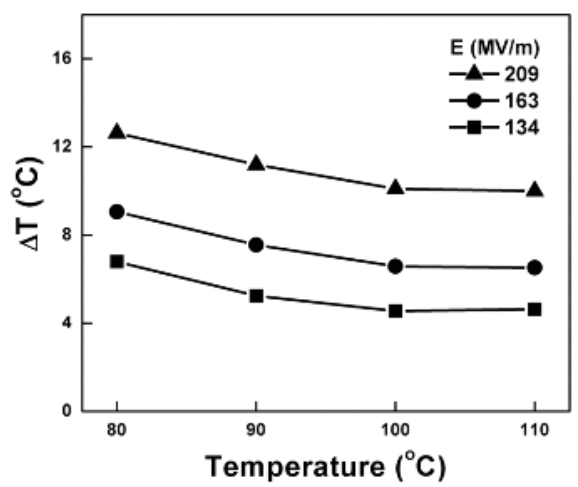

Fig. 7. Adiabatic temperature changes as a function of ambient temperature at different electric fields.

Present in Fig. 8 is the directly measured $\Delta S$ and $\Delta \mathrm{T}$ as a function of temperature measured under several electric fields for the unstretched P(VDF-TrFE) 55/45 mol\% copolymer. As can be seen, the ECE effect reaches maximum at the temperature of FE-PE transition. A comparison between the directly measured and deduced ECE indicates that within the experimental error, the ECE deduced from the Maxwell relation is consistent with that directly measured. Therefore, for a ferroelectric material at temperatures above F-P transition, Maxwell relation can be used to deduce ECE.

\subsubsection{Phenomenological calculations on ECE}

It is well established by many studies (see Fig. 2) that the F-P phase transition of P(VDFTrFE) 55/45 copolymer is of second-order. For the copolymer with $2^{\text {nd }}$ order phase transition, free energy associated with polarization can be written as

$$
\mathrm{G}=\mathrm{G}_{0}+\frac{1}{2} \beta\left(\mathrm{T}-\mathrm{T}_{\mathrm{c}}\right) \mathrm{P}^{2}+\frac{1}{4} \xi \mathrm{P}^{4}-\mathrm{EP}
$$


where $G_{0}$ is the free energy of the material not associated with polarization, $\beta$ and $\xi$ are phenomenological coefficients, that are assumed temperature independent. $T_{c}$ is the Curie temperature, $\mathrm{E}$ the electric field, and $\mathrm{P}$ the polarization.

Differentiating $G$ with respect to $P$ yields the relationship between $\mathrm{E}$ and $\mathrm{P}$,

$$
\mathrm{E}=\beta\left(\mathrm{T}-\mathrm{T}_{\mathrm{c}}\right) \mathrm{P}+\xi \mathrm{P}^{3} .
$$

When $\mathrm{E}=0$ and at $\mathrm{T}<\mathrm{T}_{\mathrm{c}}$

$$
\mathrm{P}^{2}=\beta\left(\mathrm{T}-\mathrm{T}_{\mathrm{c}}\right) / \xi .
$$

Further differentiating the Eq. (18) yields the reciprocal permittivity,

$$
\begin{gathered}
\frac{1}{\varepsilon}=\beta\left(T-T_{c}\right)+3 \xi P^{2} \quad(T<T c) . \\
\frac{1}{\varepsilon}=\beta\left(T-T_{c}\right) \quad(T \geq T c) .
\end{gathered}
$$

Using Eqs. (19) and (21), the permittivity versus temperature (Fig. 2), and the polarization versus temperature relationships (Fig. 3), $\beta$ and $\xi$ can be obtained. Their values are, $\beta=2.4 \times 10^{7}\left(\mathrm{JmC}^{-2} \mathrm{~K}^{-1}\right)$, and $\xi=3.9 \times 10^{11}\left(\mathrm{Jm}^{5} \mathrm{C}^{-4}\right)$.

Now Eq. (18) can be used to derive the polarization as a function of temperature under different DC bias fields. Before doing the calculation, it should be noted that the F-P transition temperature is a function of DC bias field. This relationship was obtained by directly measuring the permittivity as a function of temperature in different DC bias fields. The results are shown in Fig. 9.

However, the dielectric measurement becomes extremely difficult when $E_{\mathrm{DC}}>100 \mathrm{MV} / \mathrm{m}$. Hence, the relationship of $\Delta \mathrm{T}_{\mathrm{c}}-\mathrm{E}^{2 / 3}$ (Lines and Glass, 1977) was fitted and extrapolated to obtain $\mathrm{T}_{\mathrm{c}}$ at $\mathrm{E}>100 \mathrm{MV} / \mathrm{m}$.

The calculated polarization versus temperature relationships under different DC biases are shown in Fig. 10. Based on the D-T data, the $\Delta S$ and $\Delta \mathrm{T}$ can be calculated via Eqs. (6) and (7). Results are shown in Figs. 11 and 12.
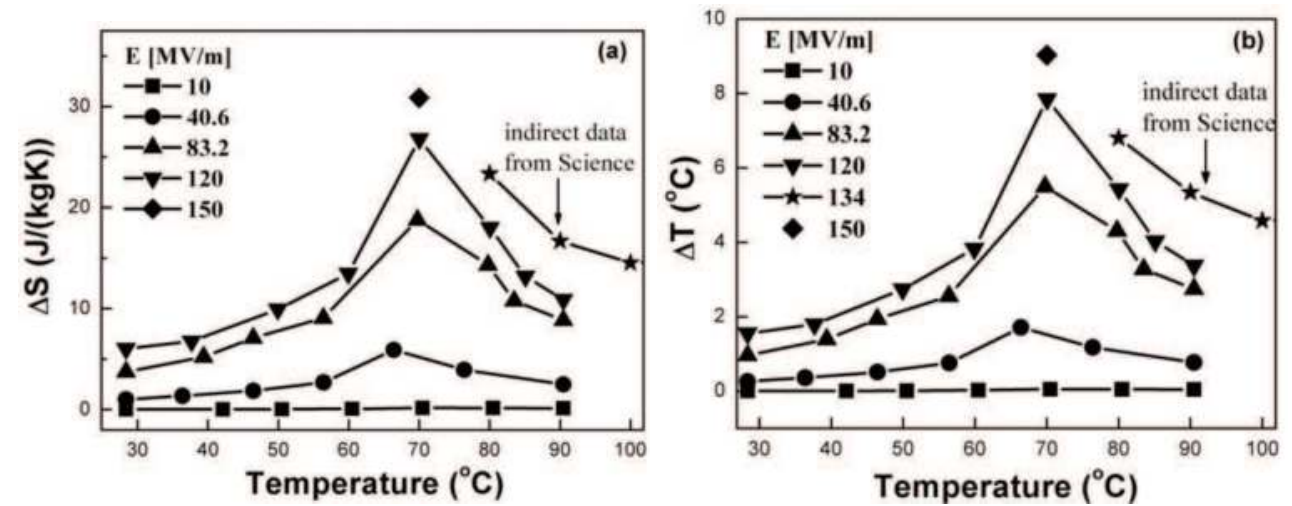

Fig. 8. Directly measured $\Delta S$ (a) and $\Delta \mathrm{T}(\mathrm{b})$ as a function of temperature under several electric fields for unstretched $\mathrm{P}(\mathrm{VDF}-\mathrm{TrFE}) 55 / 45 \mathrm{~mol} \%$ copolymers. 


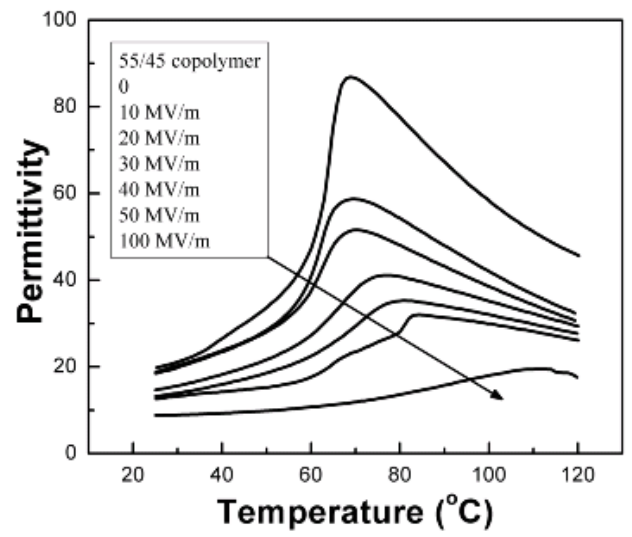

Fig. 9. Permittivity as a function of temperature at $1 \mathrm{kHz}$ in various DC bias fields for 55/45 copolymer.

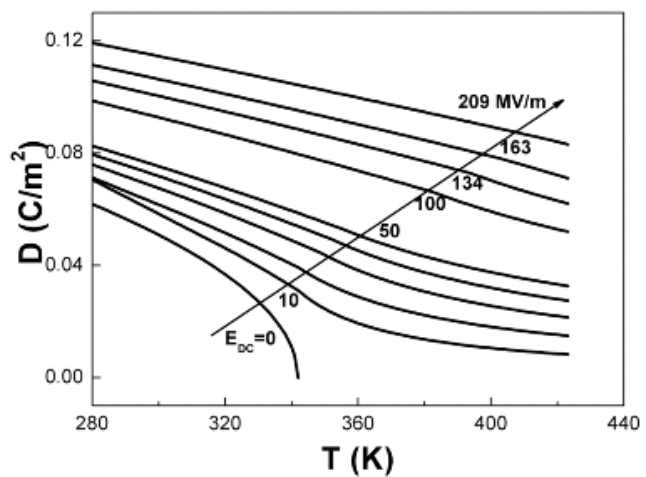

Fig. 10. Polarization versus temperature relationships with various DC biases for $55 / 45$ copolymer.

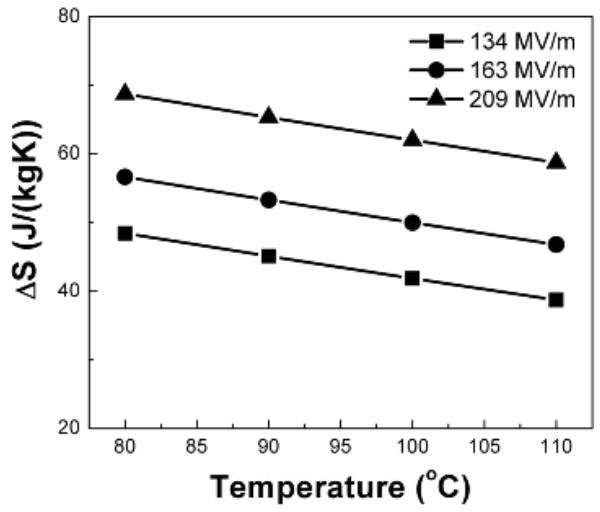

Fig. 11. ECE entropy changes versus temperature for 55/45 copolymer. 


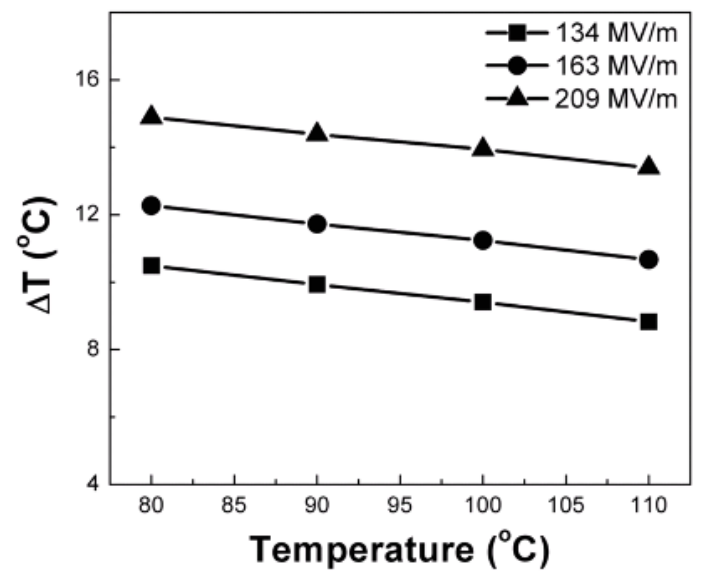

Fig. 12. ECE temperature changes versus temperature for 55/45 copolymer.

Phenomenological calculation indicates that, there is a giant ECE exhibited by P(VDF-TrFE) $55 / 45$ copolymers. The $\Delta S$ and $\Delta \mathrm{T}$ can reach $70 \mathrm{~J} /(\mathrm{kgK})$ and $15{ }^{\circ} \mathrm{C}$ respectively near the phase transition temperature $\sim 70{ }^{\circ} \mathrm{C}$. It can also be seen that $\Delta \mathrm{S}$ has a linear relationship with $\mathrm{D}^{2}$ (or $\mathrm{P}^{2}$ ), the slope is $1 / 2 \beta$.

\subsection{ECE in the relaxor ferroelectric $\mathrm{P}(\mathrm{VDF}-\mathrm{TrFE}-\mathrm{CFE})$ terpolymers}

Both the pure relaxor ferroelectric P(VDF-TrFE-CFE) 59.2/33.6/7.2 mol\% terpolymer and blends with $5 \%$ and $10 \%$ of P(VDF-CTFE) copolymer were studied. For the P(VDF-TrFE$\mathrm{CFE}$ ) relaxor terpolymer, it was observed that blending it with a small amount of P(VDFCTFE) $91 / 9 \mathrm{~mol} \%$ copolymer [CTFE: chlorotrifluoroethylene] can result in a large increase in the elastic modulus, especially at temperatures above the room temperature, which does not affect the polarization level very much. Such an increase in the elastic modulus

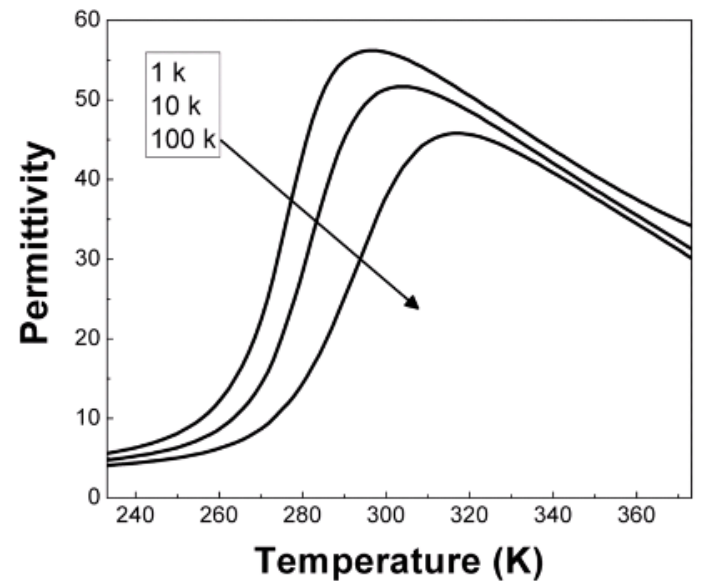

Fig. 13. Permittivity as a function of temperature at 1,10 and $100 \mathrm{kHz}$ for $59.2 / 33.6 / 7.2$ mol\% terpolymer. 


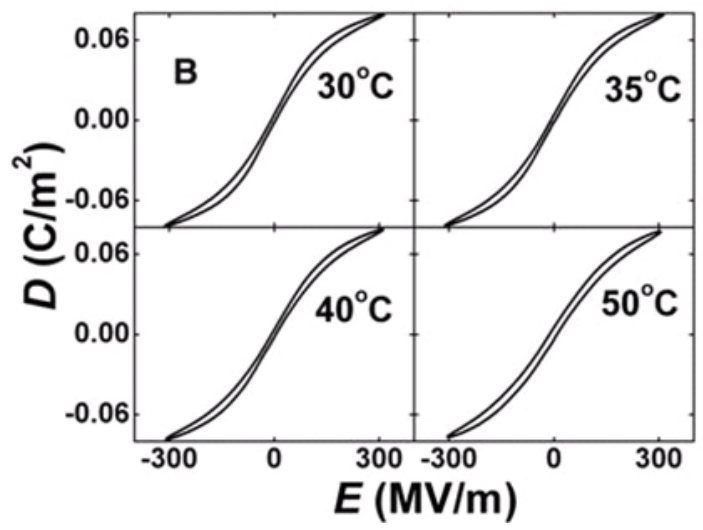

Fig. 14. Electric displacement - electric field hysteresis loops at temperature above the phase transition for 59.2/33.6/7.2 mol\% terpolymers.
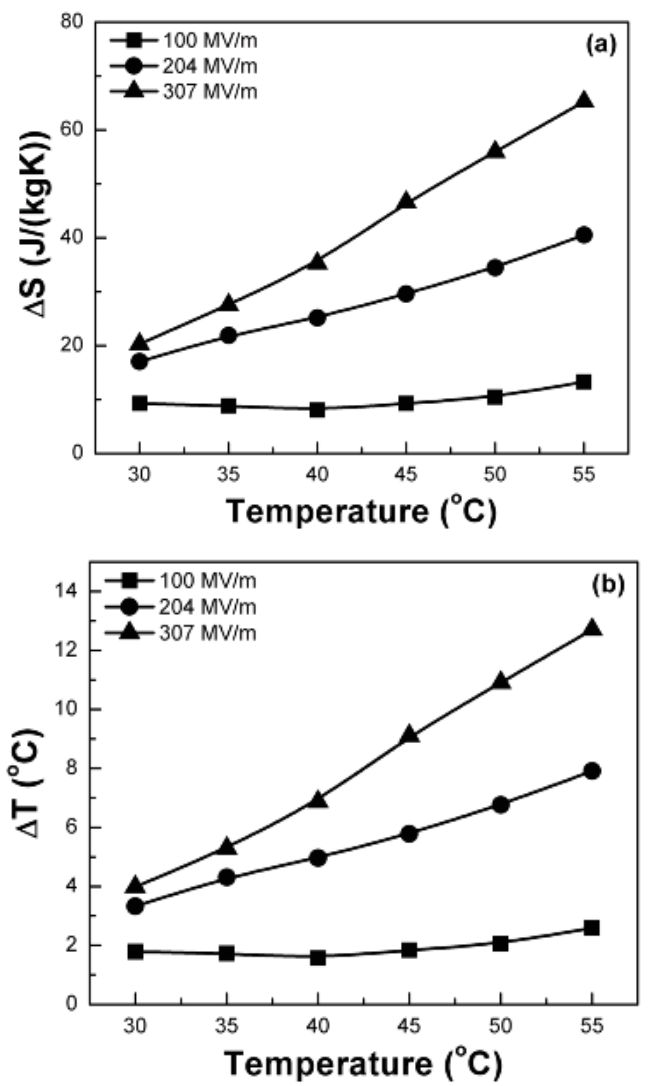

Fig. 15. ECE entropy changes (a) and temperature change (b) versus temperature deduced from Maxwell relation for 59.2/33.6/7.2 mol\% terpolymer. 
improves the dielectric strength of the blend polymer films and allows the direct measurement of ECE to be carried out to higher fields (>100 MV/m).

Present in Fig. 13 is the dielectric constant data for the terpolymer. The D-E loops for the $\mathrm{P}(\mathrm{VDF}-\mathrm{TrFE}-\mathrm{CFE}) 59.2 / 33.6 / 7.2 \mathrm{~mol} \%$ terpolymer are presented in Fig. 14, from which $\Delta S$ and $\Delta \mathrm{T}$ are deduced from the Maxwell relatoin as shown in Fig. 15 (a) and 15 (b), respectively. The results show that the terpolymer has a weak ECE at room temperature and increases with temperature. At $55{ }^{\circ} \mathrm{C}$ which is the highest temperature measured, a $\Delta S=55 \mathrm{~J} /(\mathrm{kgK})$ and $\Delta \mathrm{T}=12{ }^{\circ} \mathrm{C}$ under the field of $307 \mathrm{MV} / \mathrm{m}$ are deduced from the Maxwell relation.

The ECE from the direct measurement is presented in Fig. 16, which is for the 59.2/33.6/7.2 $\mathrm{mol} \%$ terpolymer. The data show quite different behavior compared with Fig. 15. First of all, the directly measured ECE from the relaxor terpolymer is much larger than that deduced from the Maxwell relation. Moreover, the directly measured ECE shows much weak temperature dependence at $\mathrm{E}<70 \mathrm{MV} / \mathrm{m}$.

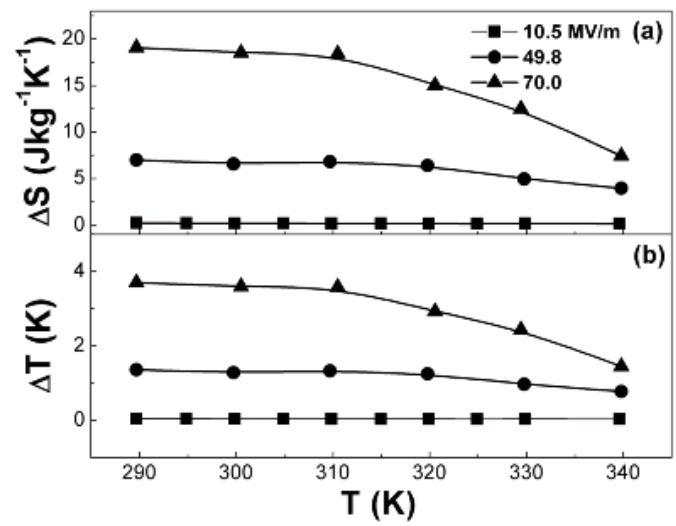

Fig. 16. Directly measured entropy changes (a) and temperature change (b) versus temperature for 59.2/33.6/7.2 $\mathrm{mol} \%$ terpolymer .

The results indicate that the Maxwell relation is not suitable for ECE characterization for the relaxor ferroelectric polymers even at temperatures above the broad dielectric constant maximum. This is likely caused by the non-ergodic behaviour of relaxor ferroelectric polymers even at temperatures above the dielectric constant maximum while the Maxwell relations are valid only for thermodynamically equilibrium systems (ergodic systems)

We also note that a recent report of ECE deduced from the Maxwell relation on a P(VDFTrFE-CFE) relaxor ferroelectric terpolymer by Liu et al. (Liu et al. 2010) shows very irregular field dependence of ECE measured at temperatures below $320 \mathrm{~K}$ where ECE in fact decreases with field, which is apparently not correct. These results all indicate that the Maxwell relation cannot be used to deduce ECE for the relaxor ferroelectric polymers, or even the relaxor ferroelectric materials in general, even at temperatures far above the freezing transition and the broad dielectric constant peak temperature.

\section{Conclusions}

General considerations for polar materials to achieve larger ECE were presented based on the phenomenological theory analysis. It is shown that in order to realize large ECE, a 
dielectric material with a large polarization $\mathrm{P}$ as well as large phenomenological coefficient $\beta$ is required. It is further shown that both the phenomenological consideration and experimental data on heat of ferroelectric-paraelectric transition suggest that ferroelectric $\mathrm{P}(\mathrm{VDF}-\mathrm{TrFE})$ based polymers have potential to achieve giant ECE. Indeed, experimental results show that the normal ferroelectric $\mathrm{P}(\mathrm{VDF}-\mathrm{TrFE}) 55 / 45 \mathrm{~mol} \%$ copolymers exhibit a large ECE, i.e., an adiabatic temperature change over $12{ }^{\circ} \mathrm{C}$ and an isothermal entropy change over $50 \mathrm{~J} /(\mathrm{kgK})$ were obtained. The experimental results also indicate that for the normal ferroelectric materials, the ECE deduced from the Maxwell relation is consistent with that directly measured.

The experimental results on ECE in the relaxor ferroelectric P(VDF-TrFE-CFE) terpolymer were also presented which reveal a very large ECE at ambient condition in the relaxor terpolymers. In contrast to the normal ferroelectric polymers, the ECE deduced from the Maxwell relation for the relaxor terpolymers significantly deviates from that directly measured. The results indicate that the Maxwell relation is not suitable for ECE characterization for the relaxor ferroelectric polymers even at temperatures above the broad dielectric constant maximum. This is likely caused by the non-ergodic behaviour of relaxor ferroelectric polymers even at temperatures above the dielectric constant maximum while the Maxwell relations are valid only for thermodynamically equilibrium systems (ergodic systems).

As a final point, one interesting question to ask when searching for electrocaloric materials to achieve giant ECE at ambient temperature is how to design dielectric materials to significantly enhance the entropy in the polar-disordered state since ECE is directly related to the entropy difference between the polar-disordered and ordered states in a dielectric material, in other words, how to design a ferroelectric material to increase $\beta$ while maintaining large D in Eqs. (9) and (10). This is certainly an interesting area of research. The successful outcome will have significant impact on the society, in terms of efficient energy use for refrigeration, new and compact cooling devices which are more environmentally friendly.

\section{Acknowledgements}

The works at Penn State University was supported by the US Department of Energy, Division of Materials Sciences, under Grant No. DE-FG02-07ER46410. The work at Jozef Stefan Institute was supported by the Slovenian Research Agency. The authors thank B. Neese, B. Chu, Y. Wang, E. Furman, Xinyu Li, and Lee J. Gorny for their contributions to the works presented in this chapter.

\section{References}

Akcay, G.; Alpay, S. P.; Mantese, J. V. \& Rossetti Jr., G. A. (2007). Magnitude of the intrinsic electrocaloric effect in ferroelectric perovskite thin films at high electric fields. Appl Phys Lett, 90 (25) (JUN, 2007), 252909/1-3. ISSN: 0003-6951.

Amin, A.; Cross, L. E. \& Newnham, R. E. (1981). Calorimetric and phenomenological studies of the $\mathrm{PbZrO}_{3}-\mathrm{PbTiO}_{3}$ system. Ferroelectrics, 37 (1-4) (1981), 647-650. ISSN: 0015-0193.

Amin, A; Newnham, R. E.; Cross, L. E. \& Cox, D. E. (1981). Phenomenological and structural study of a low-temperature phase-transition in the $\mathrm{PbZrO}_{3}-\mathrm{PbTiO}_{3}$ system. J. Solid State Chem, 37 (2) (1981), 248-255. ISSN: 0022-4596. 
Baumgartner, H. (1950). Elektrische sättigungserscheinungen und elektrokalorischer effect von kaliumphosphat $\mathrm{KH}_{2} \mathrm{PO}_{4}$. Helv Phys Acta, 23 (6-7) (1950), 651-696. ISSN: 00180238 .

Correia, T. M.; Young, J. S.; Whatmore, R. W.; Scott, J. F.; Mathur, N. D. \& Zhang, Q. (2009). Investigation of the electrocaloric effect in a $\mathrm{PbMg}_{1 / 3} \mathrm{Nb}_{2 / 3} \mathrm{O}_{3}-\mathrm{PbTiO}_{3}$ relaxor thin film. Appl Phys Lett, 95 (18) (NOV, 2009), 182904/1-3. ISSN: 0003-6951.

Dinesen, A. R.; Linderoth, S. \& Mørop, S. (2002). Direct and indirect measurement of the magnetocaloric effect in a $\mathrm{La}_{0.6} \mathrm{Ca}_{0.4} \mathrm{MnO}_{3}$ ceramic perovskite. J. Magn Magn Mater, 253 (1-2) (DEC, 2002), 28-34. ISSN: 0304-8853.

Epstein, R. \& Malloy, K. J. (2009). Electrocaloric devices based on thin-film heat switches. J Appl Phys, 106 (6) (SEP, 2009), 064509/1-7. ISSN: 0021-8979.

Furukawa, T. (1984). Phenomenological aspect of a ferroelectric vinylidene fluoride / trifluoroethylene copolymer. Ferroelectrics, 57 (1-4) (1984), 63-72. ISSN: 0015-0193.

Furukawa, T. (1989). Piezoelectricity and pyroelectricity in polymers. IEEE Trans Electr Ins, 24 (3) (JUN, 1989), 375-394. ISSN: 0018-9367.

Furukawa, T.; Nakajima, T. \& Takahashi, Y. (2006). Factors governing ferroelectric switching characteristics of thin VDF/TrFE copolymer films. IEEE Trans Diel Electr Ins, 13 (5) (OCT, 2006), 1120-1131. ISSN: 1070-9878.

Gopal, B. R.; Chahine, R. \& Bose, T. K. (1997). A sample translatory type insert for automated magnetocaloric effect measurements. Rev Sci Instrum, 68 (4) (APR, 1997), 1818-1822. ISSN: 0034-6748.

Gschneidner Jr., K. A.; Pecharsky, V. K. \& Tsokol, A. O. (2005). Recent developments in magnetocaloric materials. Rep Prog Phys, 68, 1479-1539. ISSN: 0034-4885.

Jona, F. \& Shirane, G. (1993). Ferroelectric Crystals. Dover Publications, Inc. ISBN: 0486673863, 9780486673868. New York.

Kar-Narayan, S. \& Mathur, N. (2009). Predicted cooling powers for multilayer capacitors based on various electrocaloric and electrode materials. Appl. Phys. Lett. 95, 242903/1-3.

Kobeko, Von P. \& Kurtschatov, J. (1930). Dielektrische eigenschaften der seignettesalzkristalle', Z Phys, 66, 192-205. ISSN: 0340-2347.

Kucherov, Y. R. (1997). 'Piezo-pyroelectric energy converter and method', US Patent, US 5644184.

Lang, S. B. (1976). Cryogenic refrigeration utilizing electrocaloric effect in pyroelectric lithium sulfate monohydrate. Ferroelectrics, 11 (3-4) (1976), 519-523. ISSN: 0015-0193.

Lawless, W. N. \& Morrow, A. J. (1977). Specific heat and electrocaloric properties of a $\mathrm{SrTiO}_{3}$ ceramic at low temperatures. Ferroelectrics, 15 (3-4) (1977), 159-165. ISSN: 0015-0193.

Lin, G. C.; Xu, C. D. \& Zhang, J. X. (2004). Magnetocaloric effect in $\mathrm{La}_{0.80}-\mathrm{xCa} \mathrm{a}_{0.20} \mathrm{Sr}_{x} \mathrm{MnO}_{3}$ $(x=0.05,0.08,0.10)$. J Magn Magn Mater, 283 (2-3) (DEC, 2004), 375-379. ISSN: 03048853 .

Lines, M. \& Glass, A. (1977). Principles and Applications of Ferroelectrics and Related Materials, Clarendon Press, ISBN: 0-19-851286-4. Oxford.

Liu, P. F.; Wang, J. L.; Meng, X. J.; Yang, J. Dkhil B. \& Chu, J. H. (2010). Huge electrocaloric effect in Langmuir-Blodgett ferroelectric polymer thin films. New J. Phys. 12, 023035/1-8. ISSN: 1367-2630. 
Lu, S. G., Xu, Z. K. \& Chen, H. (2005). Field-induced dielectric singularity, critical exponents, and high-dielectric tunability in [111]-oriented $(1-x) \mathrm{Pb}(\mathrm{Mg} 1 / 3 \mathrm{Nb} 2 / 3) \mathrm{O} 3-x \mathrm{PbTiO} 3$ $(x=0.24)$ Phys Rev B 72 (5) (AUG, 2005), 054120/1-4. ISSN: 1098-0121.

Mathur, N. \& Mischenko, A. (2006). Solid state electrocaloric cooling devices and methods. World Patent, WO 2006/056809.

Mischenko, A. S.; Zhang, Q.; Scott, J. F.; Whatmore, R. W. \& Mathur, N. D. (2006). Giant electrocaloric effect in thin-film $\mathrm{PbZr}_{0.95} \mathrm{Ti}_{0.05} \mathrm{O}_{3}$. Science, 311 (5765) (MAR, 2006), 1270-1271. ISSN: 0036-8075.

Neese, B.; Chu, B. J.; Lu, S. G.; Wang, Y.; Furman, E. \& Zhang, Q. M. (2008). Large electrocaloric effect in ferroelectric polymers near room temperature. Science, 321 (5890) (AUG, 2008), 821-823. ISSN: 0036-8075.

Neese, B. Ph.D. Dissertation, The Pennsylvania State University, 2009.

Newnham, R. E. (2005). Properties of Materials: anisotropy, symmetry, structure. Oxford University Press, ISBN: 019852076X/ISBN-13: 9780198520764. Oxford.

Nolas, G.; Sharp, J. \& Goldsmid, H. (2001). Thermoelectrics, Springer-Verlag, ISBN: 978-3-54041245-8. Berlin.

Pecharsky, A. O.; Gschneidner Jr., K. A. \& Percharsky, V. K. (2003). The giant magnetocaloric effect of optimally prepared $\mathrm{Gd}_{5} \mathrm{Si}_{2} \mathrm{Ge}_{2}$. J Appl Phys, 93 (8) (APR, 2003), 4722-4728. ISSN: 0021-8979.

Pecharsky, V. K.; Holm, A. P.; Gschneidner Jr., K. A. \& Rink, R. (2003). Massive magnetic-fieldinduced structural transformation in $\mathrm{Gd}_{5} \mathrm{Ge}_{4}$ and the nature of the giant magnetocaloric effect. Phys Rev Lett, 91 (19) (NOV, 2003), 197204/1-4. ISSN: 0031-9007.

Pecharsky, V. K.; Moorman, J. O. \& Gschneidner Jr., K. A. (1997). A 3-350 K fast automatic small sample calorimeter. Rev Sci Instrum, 68 (11) (NOV, 1997), 4196-4207. ISSN: 0034-6748.

PI Ceramic website: www.piceramic.de/site/piezo_002.html (accessed: January, 2009).

Provenzano, V.; Shapiro, A. J. \& Shull, R. D. (2004). Reduction of hysteresis losses in the magnetic refrigerant $\mathrm{Gd}_{5} \mathrm{Ge}_{2} \mathrm{Si}_{2}$ by the addition of iron. Nature, 429 (6994) (JUN, 2004), 853-857. ISSN: 0028-0836.

Sinyavsky, Y. V. \& Brodyansky, V. (1992). Experimental testing of electroca;loric cooling with transparent ferroelectric ceramic as a working body. Ferroelectrics, 131 (1-4) (1992), 321-325. ISSN: 0015-0193.

Sinyavsky, Y. V.; Pashkov, N. D.; Gorovoy, Y. M. \& Lugansky, G. E. \& Shebanov, L. (1989). The optical ferroelectric ceramic as working body for electrocaloric refrigeration. Ferroelectrics, 90, 213-217. ISSN: 0015-0193.

Spanner, D. C. (1951). The Peltier effect and its use in the measurement of suction pressure. J. Experm. Botany, 2 (5), 145-168. ISSN: 0022-0957.

Spichkin, Y. I.; Derkach, A. V.; Tishin, A. M.; Kuz'min, M. D.; Chernyshov, A. S.; Gschneidner Jr., K. A. \& Pecharsky, V. K. (2007). Thermodynamic features of magnetization and magnetocaloric effect near the magnetic ordering temperature of Gd. J. Magn Magn Mater, 316 (2) (SEP, 2007), e555-e557. ISSN: 0304-8853.

Tocado, L.; Palacios, E. \& Burriel, R. (2005). Direct measurement of the magnetocaloric effect in $\mathrm{Tb}_{5} \mathrm{Si}_{2} \mathrm{Ge}_{2}$. J Magn Magn Mater, 290-291 (Part 1, SP. Iss SI) (APR, 2005), 719-722. ISSN: 0304-8853. 
Tuttle, B. A. \& Payne, D. A. (1981). The effect of microstructure on the electrocaloric properties of $\mathrm{Pb}(\mathrm{Zr}, \mathrm{Sn}, \mathrm{Ti}) \mathrm{O}_{3}$ ceramics. Ferroelectrics, 37 (1-4) (1981), 603-606. ISSN: 0015-0193.

Wiseman, G. G. \& Kuebler, J. K. (1963). Electrocaloric effect in ferroelectric Rochelle salt. Phys Rev, 131 (5) (1963), 2023-2027. ISSN: 0013-899X.

Wood, M. E. \& Potter, W. H. (1985). General analysis of magnetic refrigeration and its optimization using a new concept: maximization of refrigerant capacity. Cryogenics, 25 (12) (DEC, 1985), 667-683. ISSN: 0011-2275.

Xiao, D. Q.; Wang, Y. C.; Zhang, R. L.; Peng, S. Q.; Zhu, J. G. \& Yang, B. (1998). Electrocaloric properties of (1-x) $\mathrm{Pb}\left(\mathrm{Mg}_{1 / 3} \mathrm{Nb}_{2 / 3}\right) \mathrm{O}_{3}-\mathrm{xPbTiO}_{3}$ ferroelectric ceramics near room temperature. Mater Chem Phys, 57 (2) (DEC, 1998), 182-185. ISSN: 0254-0584.

Yao, H.; Ema, K. \& Garland, C. W. (1998). Nonadiabatic scanning calorimeter. Rev Sci Instrum, 69 (1) (JAN, 1998), 172-178. ISSN: 0034-6748.

Ye, Z. G. \& Schmid, H. (1993). Optical dielectric and polarization studies of the electric fieldinduced phase transition in $\mathrm{Pb}\left(\mathrm{Mg}_{1 / 3} \mathrm{Ng}_{2 / 3}\right) \mathrm{O}_{3}$ [PMN]. Ferroelectrics, 145 (1) (AUG, 1993), 83-108. ISSN: 0015-0193. 


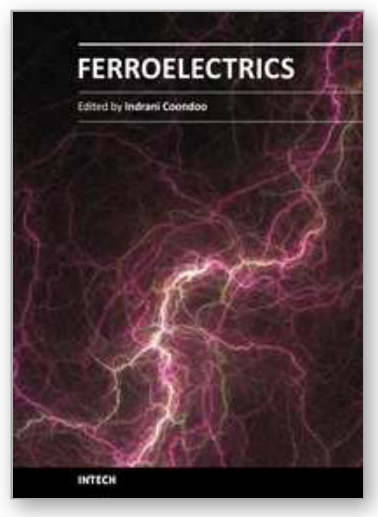

\author{
Ferroelectrics \\ Edited by Dr Indrani Coondoo
}

ISBN 978-953-307-439-9

Hard cover, 450 pages

Publisher InTech

Published online 14, December, 2010

Published in print edition December, 2010

Ferroelectric materials exhibit a wide spectrum of functional properties, including switchable polarization, piezoelectricity, high non-linear optical activity, pyroelectricity, and non-linear dielectric behaviour. These properties are crucial for application in electronic devices such as sensors, microactuators, infrared detectors, microwave phase filters and, non-volatile memories. This unique combination of properties of ferroelectric materials has attracted researchers and engineers for a long time. This book reviews a wide range of diverse topics related to the phenomenon of ferroelectricity (in the bulk as well as thin film form) and provides a forum for scientists, engineers, and students working in this field. The present book containing 24 chapters is a result of contributions of experts from international scientific community working in different aspects of ferroelectricity related to experimental and theoretical work aimed at the understanding of ferroelectricity and their utilization in devices. It provides an up-to-date insightful coverage to the recent advances in the synthesis, characterization, functional properties and potential device applications in specialized areas.

\title{
How to reference
}

In order to correctly reference this scholarly work, feel free to copy and paste the following:

S. G. Lu, B. Rozic, Z. Kutnjak and Q. M. Zhang (2010). Electrocaloric Effect (ECE) in Ferroelectric Polymer Films, Ferroelectrics, Dr Indrani Coondoo (Ed.), ISBN: 978-953-307-439-9, InTech, Available from: http://www.intechopen.com/books/ferroelectrics/electrocaloric-effect-ece-in-ferroelectric-polymer-films

\section{INTECH}

open science | open minds

\section{InTech Europe}

University Campus STeP Ri

Slavka Krautzeka 83/A

51000 Rijeka, Croatia

Phone: +385 (51) 770447

Fax: +385 (51) 686166

www.intechopen.com

\section{InTech China}

Unit 405, Office Block, Hotel Equatorial Shanghai No.65, Yan An Road (West), Shanghai, 200040, China 中国上海市延安西路65号上海国际贵都大饭店办公楼 405 单元 Phone: +86-21-62489820

Fax: +86-21-62489821 
(C) 2010 The Author(s). Licensee IntechOpen. This chapter is distributed under the terms of the Creative Commons Attribution-NonCommercialShareAlike-3.0 License, which permits use, distribution and reproduction for non-commercial purposes, provided the original is properly cited and derivative works building on this content are distributed under the same license. 